\title{
Predictors of 90-day mortality after congenital heart surgery: The first report of risk models from a Japanese database
}

\author{
Hiroaki Miyata, PhD, Arata Murakami, MD, PhD, Ai Tomotaki, RNs, MSc, Tetsuhiro Takaoka, MD, \\ Takeshi Konuma, MD, PhD, Goki Matsumura, MD, PhD, Syunji Sano, MD, PhD, and \\ Shinichi Takamoto, MD, PhD
}

Objective: The purpose of this study was to develop risk models for congenital heart surgery short-term and midterm outcomes from a nationwide integrated database drawn from hospitals in Japan.

\begin{abstract}
Methods: The Japan Congenital Cardiovascular Surgery Database collects clinical information from institutions throughout Japan specializing in congenital heart surgery. Variables and definitions used in the Japan Congenital Cardiovascular Surgery Database are almost identical to those of the Society of Thoracic Surgeons-European Association for Cardiothoracic Surgery database for congenital heart surgery. We used logistic regression to develop risk models, which were then validated through spilt-sample validation. In addition to procedural complexity categories by Risk Adjustment in Congenital Heart Surgery (RACHS-1) score, we incorporated patient characteristics to predict surgical outcome.
\end{abstract}

Results: Among 8923 congenital heart operations performed at 69 sites with cardiac surgical programs, 30-day mortalities by RACHS-1 category were as follows: I, $0.1 \%(\mathrm{n}=1319)$; II, $0.5 \%(\mathrm{n}=3211)$; III, $2.2 \%$ $(\mathrm{n}=3285) ;$ IV, 4.3\% $(\mathrm{n}=818)$; and V and VI, 8.6\% $(\mathrm{n}=290)$. From the test data set $(\mathrm{n}=7223)$, we developed 3 risk models (30-day mortality, 90-day mortality, and 90-day and in-hospital mortality) with 11 variables, including age category, RACHS- 1 category, preoperative risk factors, number of surgical procedures, unplanned reoperations, status of surgery, surgery type, asplenia, and prematurity ( $<35$ weeks). For the performance metrics of the risk models, C statistic values of 30-day, 90-day, and 90-day and in-hospital mortalities for the test data set were $0.85,0.85$, and 0.84 , respectively. When only the RACHS-1 score was used for discrimination, the C statistic values of 30-day, 90-day, and 90-day and in-hospital mortalities for the validation data set were $0.73,0.73$, and 0.77 , respectively.

Conclusions: The proposed risk scores and categories have high discrimination power for predicting mortality, demonstrating improvement relative to existing consensus-based methods. Risk models incorporating these measures may be useful for comparing mortality outcomes cross institutions or countries with mixed cases. (J Thorac Cardiovasc Surg 2014;148:2201-6)

See related commentary on pages 2206-7.

Congenital heart surgery is one of the most challenging areas in the entire field of surgery. This may be particularly true for open palliative procedures with cardiopulmonary bypass in immature neonates with complex congenital heart disease. Open repair in adult patients with congenital heart

\footnotetext{
From the Japan Cardiovascular Surgery Database Organization, Tokyo, Japan. Funded by a Grant-in-Aid for Scientific Research, the Ministry of Education, Culture, Sports, Science and Technology, Japan.

Disclosures: Authors have nothing to disclose with regard to commercial support. Received for publication Sept 17, 2012; revisions received Dec 12, 2012; accepted for publication Jan 14, 2013.

Address for reprints: Hiroaki Miyata, $\mathrm{PhD}$, Department of Healthcare Quality Assessment, Graduate School of Medicine, The University of Tokyo, 7-3-1 Hongo, Bunkyo-ku, Tokyo, Japan (E-mail: hqa-adm@umin.ac.jp). $0022-5223 / \$ 36.00$

Copyright (c) 2014 by The American Association for Thoracic Surgery http://dx.doi.org/10.1016/j.jtcvs.2013.01.053
}

disease also carries a high risk associated with multiorgan dysfunction because of long-standing cyanosis. The Society of Thoracic Surgeons-European Association for Cardiothoracic Surgery database for congenital heart surgery lists 148 types of surgical procedures. ${ }^{1}$ The need to establish clinical registries and quantitative tools for responsible outcome reporting has been recognized.

Previous risk classification of complex congenital heart surgery has been based on complexity scores, rather than surgical procedure-based classification. Satisfactory mortality prediction can be achieved with Society of Thoracic Surgeons-European Association for Cardiothoracic Surgery scores and categories (C statistics 0.784 and 0.733 , respectively). ${ }^{1}$ With respect to procedural complexity, the Risk Adjustment in Congenital Heart Surgery (RACHS$1)^{2,3}$ and Aristotle ${ }^{4,5}$ basic scores are used in the Society of Thoracic Surgeons and European Association for Cardiothoracic Surgery databases. ${ }^{6}$ Each score is decided on by a committee composed of specialists, meaning that it is derived from subjective indicators that do not account 


\section{Abbreviations and Acronyms \\ JCCVSD = Japan Congenital Cardiovascular Surgery Database \\ RACHS-1 = Risk Adjustment in Congenital Heart Surgery}

for patient factors. ${ }^{2-5}$ In this study, we examined the validity of risk stratification according to procedural complexity by using data. The development of an objective model with high reproducibility is desired for benchmarking purposes. ${ }^{7,8}$ In addition to incorporating the procedural complexity indicators mentioned previously, we also included patient-derived risk factors to develop an explanatory, objective model. Moreover, whereas previous studies have used in-hospital mortality for benchmarking, ${ }^{9}$ we also incorporated 90-day mortality to assess longer-term outcomes than previously addressed.

\section{MATERIALS AND METHODS Study Population}

In 2000, the Japanese Society for Cardiovascular Surgery established a nationwide database to assess surgical outcomes after cardiovascular surgery. In 2008, the Society launched the Japan Congenital Cardiovascular Surgery Database (JCCVSD) for congenital heart surgery. ${ }^{10}$ The JCCVSD currently collects clinical information from 82 Japanese institutions specializing in congenital heart disease, covering almost all major congenital heart surgery programs in Japan. Each participating hospital has received the appropriate approval from the respective institutional review board.

Eight-two sites have participated in the JCCVSD, and 64 sites of these sites submitted the data of 2008 through 2010. Items in the database include demographic information, cardiac and noncardiac anomalies, comorbid conditions, and surgical type and outcomes. Definitions of these variables are essentially identical to those of the Society of Thoracic Surgeons database ${ }^{11}$ (definitions are available online at http://sts.org). The JCCVSD has developed a web-based datacollection software system through which the data manager of each participating hospital can electronically submit data to the central office. Validity of the data sets has been confirmed by an independent comparison of the volume of cardiac surgery at a particular hospital entered in the JCCVSD versus that reported to the Japanese Association for Thoracic Surgery annual survey. ${ }^{12}$

We examined all congenital heart surgical procedures reported between August 1, 2008, and December 31, 2010. JCCVSD records obtained without patient consent were excluded from this analysis. We included 9401 records with age (or age range), sex, and 90-day status and excluded 2045 for which the RACHS-1 score was unavailable. On the basis of RACHS-1 scores, ${ }^{2,3}$ we included only the operation with the highest RACHS-1 score for each hospital admission, excluding other surgical procedures $(n=478)$ within the same admission. In the end, the population for this analysis comprised 8923 congenital heart surgical procedures from 69 participating institutions throughout Japan.

With respect to risk factors, although the vast majority of JCCVSD patient are young, there are some adult congenital heart surgical cases. Although we added age category as a general risk factor, it is better to add acquired risk factors when assessing the adult population. Further research might better to consider this matter. Also, because of the limitation of low event rate, we used a large category of preoperative risk factor to examine risk in the JCCVSD at the initial phase.

\section{End Points}

The primary outcome measure of JCCVSD was 30-day mortality, which included any patient who died during the index hospitalization as of day 30 after the operation, regardless of the length of the hospital stay, and any patient who died after being discharged from the hospital within 30 days of the operation. The secondary outcomes of the JCCVSD were 90-day mortality and 90-day and in-hospital mortality. The 90-day mortality was defined as death within 90 days after the operation, regardless of in-hospital or out-ofhospital status. The 90-day and in-hospital mortality included any death during the index hospitalization, regardless of length of hospital stay, and any death occurring out of the hospital within 90 days after surgery.

\section{Statistical Analysis}

Data $(\mathrm{n}=8923)$ were randomly divided into 2 subsets for model development, the test data set (7223 records; $80 \%$ ) and the validation data set (1700 records; $20 \%$ ). For the test data set, multivariate stepwise logistic regression analysis (forward inclusion method) was performed for each outcome. For the validation data set, the area under the receiver operating characteristic curve ${ }^{13}$ was used to assess the discrimination power of the risk model for predicting patient mortality. Model calibration (the degree of similarity between observed outcomes and outcomes predicted by the model, compared across patient groups) was examined by comparing the observed and predicted averages within each of equally sized subgroups arranged in increasing order of patient risk.

\section{RESULTS \\ Risk Profile of the Study Population}

The patient population (total JCCVSD records, $\mathrm{n}=8923$ ) was classified according to RACHS- 1 category ${ }^{2,3}$ (category I, 1319; category II, 3211; category III, 3285; category IV, 818; category V, 4; and category VI, 286; Table 1). Of the patient population, $51.5 \%$ were male; $13.7 \%$ were neonates, $37.5 \%$ were infants, and $5.6 \%$ were adults; $26.8 \%$ were undergoing palliative operations and $73.2 \%$ were undergoing corrective operations; $6.2 \%$ had a birth weight lower than $2000 \mathrm{~g} ; 2.2 \%$ were undergoing noninitial procedures; $68.4 \%$ were undergoing procedures with any preoperative risk factor; $2.1 \%$ had asplenia syndrome; and $0.5 \%$ were born at 32 to 35 weeks' gestation. The average hospital stays were $25.7 \pm 37.3$ days in the test data set and $26.0 \pm$ 41.2 days in the validation data set.

\section{Outcome Rates}

Table 2 shows an abbreviated risk profile for the JCCVSD study population. Outcome rates associated with congenital heart surgery were $1.7 \%$ for 30 -day mortality, $2.4 \%$ for 90 day mortality, and $2.8 \%$ for 90 -day and in-hospital mortality. Outcome rates by RACHS- 1 score (category I, II, III, IV, and $\mathrm{V}$ and $\mathrm{VI}$ combined) for 30-day mortality were $0.1 \%$, $0.5 \%, 2.2 \%, 4.3 \%$, and $8.6 \%$, respectively; those for 90 day and in-hospital mortality were $0.2 \%, 0.7 \%, 3.0 \%$, $5.5 \%$, and $15.2 \%$, respectively.

\section{Model Results}

Three different risk models (30-day mortality, 90-day mortality, and 90-day and in-hospital mortality) were 
TABLE 1. Patient characteristics $(n=8923)$

\begin{tabular}{|c|c|c|c|c|c|}
\hline & \multicolumn{2}{|c|}{$\begin{array}{l}\text { Test data set } \\
(\mathrm{n}=\mathbf{7 2 2 3})\end{array}$} & \multicolumn{2}{|c|}{$\begin{array}{l}\text { Validation data set } \\
\quad(\mathbf{n}=\mathbf{1 7 0 0})\end{array}$} & \multirow{2}{*}{$\begin{array}{c}P \\
\text { value } \\
\end{array}$} \\
\hline & $\mathbf{n}$ & $\%$ & n & $\%$ & \\
\hline RACHS- 1 category & & & & & .989 \\
\hline I & 1061 & 14.7 & 258 & 15.2 & \\
\hline II & 2601 & 36.0 & 610 & 35.9 & \\
\hline III & 2663 & 36.9 & 622 & 36.6 & \\
\hline IV & 663 & 9.2 & 155 & 9.1 & \\
\hline $\mathrm{V}$ & 3 & 0.04 & 1 & 0.1 & \\
\hline VI & 232 & 3.2 & 54 & 3.2 & \\
\hline \multicolumn{6}{|l|}{ Age } \\
\hline$<28 \mathrm{~d}$ & 980 & 13.6 & 241 & 14.2 & .505 \\
\hline $28 \mathrm{~d}-1 \mathrm{y}$ & 2695 & 37.3 & 654 & 38.5 & .373 \\
\hline $1-18$ y & 3144 & 43.5 & 704 & 41.4 & .115 \\
\hline$\geq 18$ y & 400 & 5.5 & 100 & 5.9 & .598 \\
\hline \multicolumn{6}{|l|}{ Mortality } \\
\hline $30-d$ & 123 & 1.7 & 28 & 1.6 & 1.000 \\
\hline $90-d$ & 168 & 2.3 & 210 & 2.4 & .722 \\
\hline In-hospital & 204 & 2.8 & 48 & 2.8 & 1.000 \\
\hline 90-d and in-hospital & 223 & 3.1 & 57 & 3.4 & .588 \\
\hline Male sex & 3694 & 51.1 & 904 & 53.2 & .138 \\
\hline Preterm pregnancy & 572 & 7.9 & 144 & 8.5 & .457 \\
\hline Fetal diagnosis & 1251 & 17.3 & 289 & 17.0 & .775 \\
\hline Birth weight $<2000 \mathrm{~g}$ & 444 & 6.1 & 111 & 6.5 & .577 \\
\hline Any preoperative risk factor & 4922 & 68.1 & 1185 & 69.7 & .223 \\
\hline$\geq 2$ surgical procedures & 159 & 2.2 & 39 & 2.3 & .794 \\
\hline Unplanned reoperations & 489 & 6.8 & 130 & 7.6 & .203 \\
\hline$\geq 2$ hospitalizations & 633 & 8.8 & 134 & 7.9 & .269 \\
\hline \multicolumn{6}{|l|}{ Status of surgery } \\
\hline Urgent & 567 & 7.8 & 126 & 7.4 & .580 \\
\hline Emergency & 148 & 2.0 & 48 & 2.8 & .053 \\
\hline \multicolumn{6}{|l|}{ Surgery type } \\
\hline Without CPB & 1182 & 16.4 & 264 & 15.5 & .421 \\
\hline Nonradical & 1933 & 26.8 & 456 & 26.8 & .976 \\
\hline Asplenia & 145 & 2.0 & 43 & 2.5 & .188 \\
\hline Down syndrome & 282 & 3.9 & 67 & 3.9 & .945 \\
\hline Polysplenia & 58 & 0.8 & 11 & 0.6 & .644 \\
\hline \multicolumn{6}{|l|}{ Prematurity } \\
\hline$<32 \mathrm{wk}$ & 14 & 0.2 & 5 & 0.3 & .387 \\
\hline $32-35 \mathrm{wk}$ & 33 & 0.5 & 8 & 0.5 & 1.000 \\
\hline
\end{tabular}

RACHS-1, Risk Adjustment in Congenital Heart Surgery [score]; $C P B$, cardiopulmonary bypass.

developed. The final logistic models with odd ratios and $95 \%$ confidence intervals are presented in Table 2 . We included 11 variables as adjustment factors for the final risk models, such as age ( $<28$ days and $<28$ days $)$, RACHS-1 category (I, II, III, IV, and V and VI combined), birth weight $(<2000 \mathrm{~g})$, the presence of preoperative risk factors, the number of procedure $(>2)$, unplanned reoperation, status of surgery (urgent and emergency), surgery type (nonradical), asplenia, and prematurity ( $<35$ weeks). We defined a nonradical operation as any palliative operation. For example, nonradical operations would include Blalock-Taussig shunt for cyanotic congenital heart disease.

\section{Model Performance}

C statistic values for 30-day, 90-day, and 90-day and in-hospital mortalities for the validation data set were $0.79,0.81$, and 0.84 , respectively; for the test data set, they were $0.83,0.85$, and 0.84 respectively. When only the RACHS-1 score was used, C statistic values for 30-day, 90-day, and 90-day and in-hospital mortalities for the validation data set were $0.73,0.73$, and 0.77 , respectively; for the test data set, they were $0.76,0.78$, and 0.77 , respectively.

\section{Observed Versus Predicted Mortality}

The comparison of predicted and observed mortality by risk categories for 30-day mortality, 90-day mortality, and 90-day and in-hospital mortality are shown in Figures 1 through 3. For 30-day mortality, observed mortality and predicted mortality were 0.0072 and 0.0310 (risk $>0.5 \%$ ), 0.0050 and $0.0068(0.5 \%-1.0 \%), 0.0063$ and 0.0124 $(1.9 \%-2.0 \%), 0.0318$ and $0.0265(2.0 \%-4.0 \%), 0.0710$ and 0.0576 (4.0\%-8.0\%), and 0.1416 and 0.1792 $(\geq 8.0 \%)$, respectively (Figure 1). For 90-day and inhospital mortality, observed mortality and predicted mortality were 0.0036 and $0.0049(>1.0 \%), 0.0095$ and 0.0143 $(1.0 \%-2.0 \%), 0.0234$ and $0.0308(2.0 \%-4.0 \%), 0.0753$ and $0.0642(4.0 \%-8.0 \%), 0.1765$ and $0.1277(8.0 \%$ $16.0 \%)$, and 0.2239 and $0.2964(\geq 16.0 \%)$, respectively (Figure 3).

\section{DISCUSSION}

The risk model that incorporated patient characteristics in procedural complexity categories was more discriminating than a model that solely used procedural complexity categories. When only the RACHS- 1 score was used, discriminating power was relatively satisfactory at 0.73 to 0.77. This discriminating power was similar to that seen with the population of the region in which RACHS-1 was designed, ${ }^{3}$ suggesting that procedural complexity categories can also be applied to Japanese populations. Moreover, after incorporation of patient-derived factors such as age categories, preoperative weight, and preoperative risk factors, the $\mathrm{C}$ statistic values of models with 0.5 increased to more than 0.5 , reflecting an increase in discriminating power. The mortality predicted by our risk model and the observed mortality were similar in both low-risk and high-risk groups, suggesting that our calibration was also valid to a certain degree. These findings suggest that a risk model that incorporates patient characteristics in procedural complexity categories according to RACHS-1 presents a useful framework for calculating predicted mortality.

In this study, a risk model was developed for 90-day mortality and in-hospital mortality in addition to 30-day mortality. A satisfactory 30-day mortality can be attributed 
TABLE 2. Description of risk models $(n=7223)$

\begin{tabular}{|c|c|c|c|c|c|c|}
\hline & \multicolumn{2}{|c|}{ 30-d mortality } & \multicolumn{2}{|c|}{ 90-d mortality } & \multicolumn{2}{|c|}{ 90-d and in-hospital mortality } \\
\hline & OR & $95 \%$ CI & OR & $\mathbf{9 5} \%$ CI & OR & $\mathbf{9 5} \% \mathbf{C I}$ \\
\hline Age $<28 \mathrm{~d}$ & 2.21 & $1.47-3.32$ & 1.88 & $1.28-2.75$ & 2.25 & $1.64-3.09$ \\
\hline RACHS-1 category (I, II, III, IV, and V plus VI) & 1.98 & $1.62-2.43$ & 2.35 & $1.97-2.82$ & 2.08 & $1.76-2.48$ \\
\hline Birth weight $<2000 \mathrm{~g}$ & - & - & 2.23 & $1.32-3.78$ & 1.99 & $1.21-3.26$ \\
\hline Any preoperative risk factor & 2.31 & $1.36-3.91$ & 1.80 & $1.17-2.77$ & 1.94 & $1.34-2.82$ \\
\hline$\geq 2$ surgical procedures & - & - & - & - & 1.96 & $1.19-3.22$ \\
\hline Unplanned reoperations & 1.96 & $1.10-3.57$ & 2.00 & $1.18-3.38$ & 2.12 & $1.34-3.36$ \\
\hline \multicolumn{7}{|l|}{ Status of surgery } \\
\hline Urgent & - & - & 1.56 & $1.00-2.44$ & - & - \\
\hline Emergency & 4.13 & $2.34-7.28$ & 4.52 & $2.62-7.77$ & 3.46 & $2.12-5.65$ \\
\hline Nonradical surgery & 2.83 & $1.89-4.25$ & 2.74 & $1.92-3.91$ & 2.67 & $1.95-3.65$ \\
\hline Asplenia & - & - & - & - & 3.86 & $2.08-7.17$ \\
\hline Prematurity & 4.27 & $0.97-18.7$ & - & - & 4.39 & $1.51-12.8$ \\
\hline
\end{tabular}

$O R$, Odds ratio; $C I$, confidence interval; $R A C H S$ - 1 , Risk Adjustment in Congenital Heart Surgery [score].

to the adequate provision of resources for hospital care, such as postoperative intensive care, and is reflected by long-term hospitalization that lasts on average 1 month, because mortality may be related to prolonged stay. ${ }^{14}$ This exemplifies the characteristics of the Japanese health care system, and similar trends have been reported in the field of adult cardiac surgery. ${ }^{15}$ Because long-term hospitalization is connected to the inefficient use of medical resources, ${ }^{16}$ cost efficiency should also be considered in the future. Moreover, most deaths within 90 days occurred within the hospitalization period. This is connected to the fact that there were fewer missing values for variables that tend to be missing from foreign databases, such as 30-day mortality and 90-day mortality. ${ }^{17}$ Although there is very little difference in included items and odds ratios for risk models of 30-day mortality and 90-day and inhospital mortality, emergency surgery tends to have a relatively large effect on 30-day mortality, whereas birth weight and number of procedures tend to have a large effect on 90-day mortality. In light of the approximately 2fold gap between 30-day and 90-day mortalities, it will be important to consider how to address patients who die within this period. ${ }^{18}$

Although our risk models showed good performance, there is still room for improvement. First, with respect to 90-day and in-hospital mortality, the model simultaneously overestimated the risk in the group with a predicted mortality greater than $16 \%$ and underestimated the risk in the group with a predicted mortality of $8 \%$ to $16 \%$. Thus improving accuracy for high-risk groups will be important.

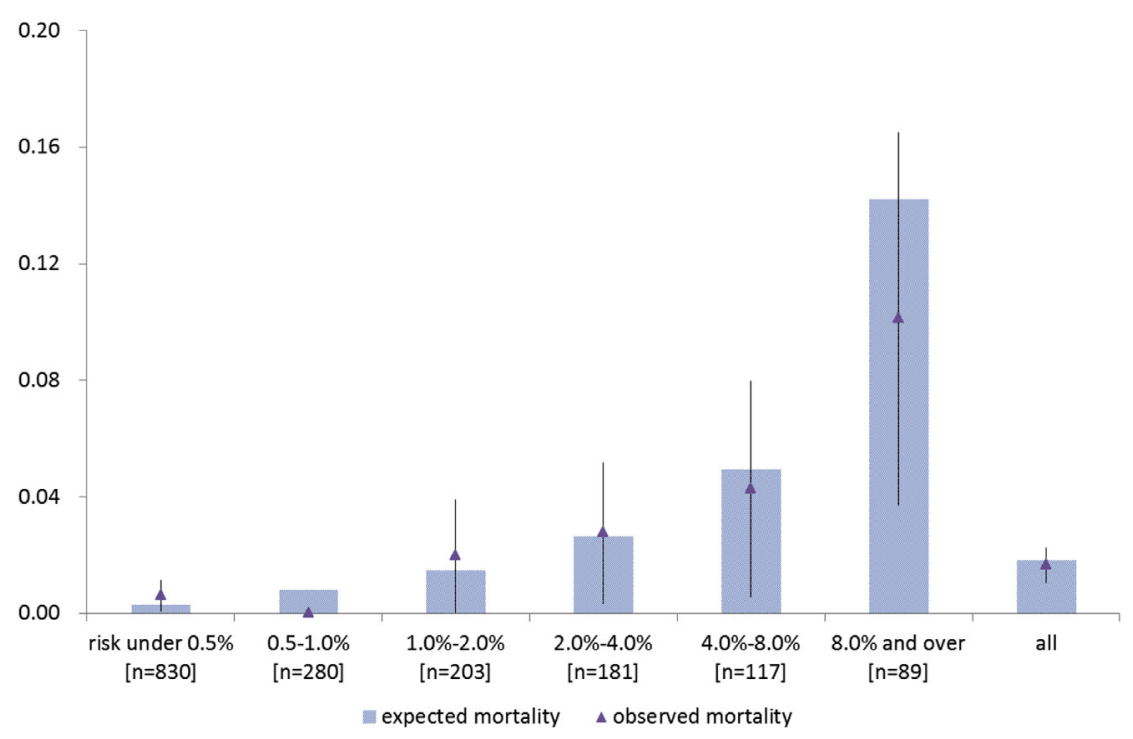

FIGURE 1. Predicted and observed 30-day mortality by risk categories. 


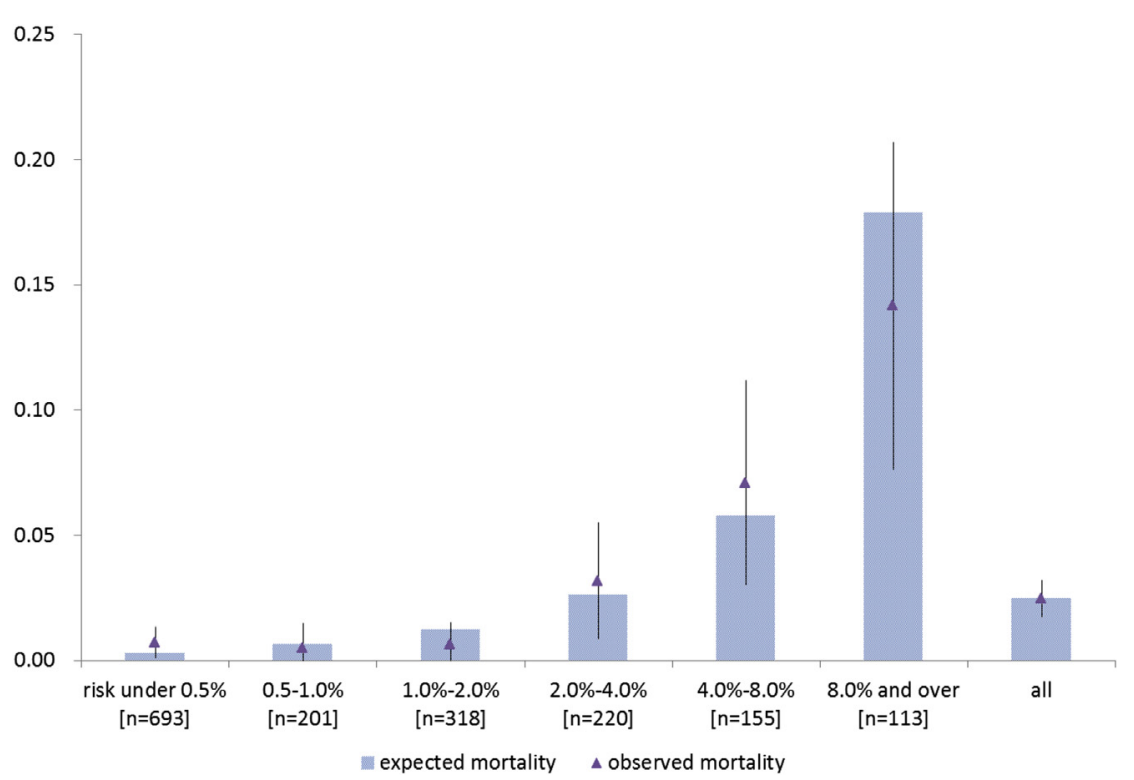

FIGURE 2. Predicted and observed 90 -day mortality by risk categories.

Second, a better risk model might also be developed by not only restructuring highly complex procedural categories but also considering patient characteristics that contribute to high risk. Because of the limitation of low event rate, we used large category, preoperative risk factor, to examine risk in the JCCVSD in the initial phase. In addition, although the vast majority of the JCCVSD patient are youths, there are some adult congenital heart procedures. Although we added age category as general risk factor, it is better to add acquired risk factors when assessing the adult population. Further research might allow us to consider this matter more fully. For procedural complexity categories, calibration was increased, and discrimination did not differ when the categories were considered by increasing order of patient risk rather than by using the ordinal variables as each degree of complexity, which is why the former strategy was used. Third, death was the only outcome of this study. When considering the performance of pediatric cardiac surgical practice in its entirety, understanding complications is crucial. ${ }^{19}$ In this context, focusing on complications and longer-term prognosis will likely be an effective strategy.

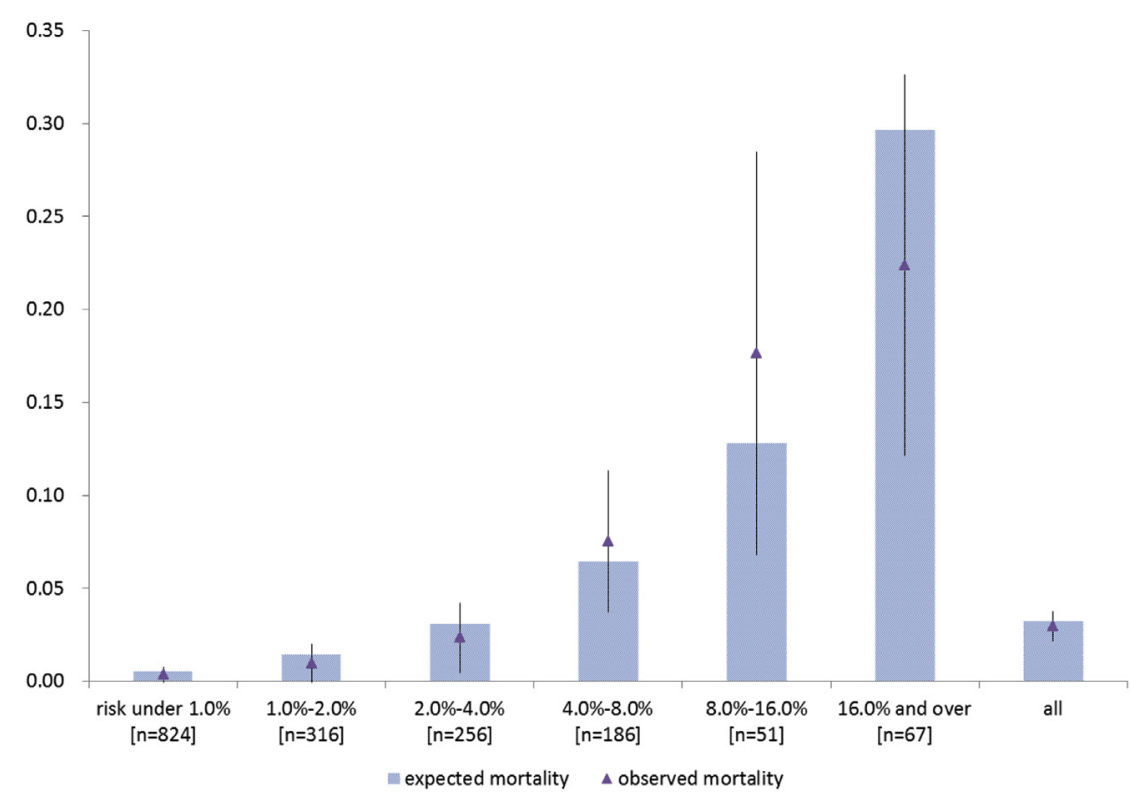

FIGURE 3. Predicted and observed 90-day and in-hospital mortality by risk categories. 


\section{References}

1. O'Brien SM, Clarke DR, Jacobs JP, Jacobs ML, Lacour-Gayet FG, Pizarro C, et al. An empirically based tool for analyzing mortality associated with congenital heart surgery. J Thorac Cardiovasc Surg. 2009;138:1139-53.

2. Jenkins KJ, Gauvreau K, Newburger JW, Spray TL, Moller JH, Iezzoni LI Consensus-based method for risk adjustment for surgery for congenital heart disease. J Thorac Cardiovasc Surg. 2002;123:110-8.

3. Jenkins KJ, Gauvreau K. Center-specific differences in mortality: preliminary analyses using the Risk Adjustment in Congenital Heart Surgery (RACHS-1) method. J Thorac Cardiovasc Surg. 2002;124:97-104.

4. Lacour-Gayet F, Clarke D, Jacobs J, Comas J, Daebritz S, Daenen W, et al. The Aristotle score: a complexity-adjusted method to evaluate surgical results. Eur J Cardiothorac Surg. 2004;25:911-24.

5. Lacour-Gayet F, Clarke D, Jacobs J, Gaynor W, Hamilton L, Jacobs M, et al. The Aristotle score for congenital heart surgery. Semin Thorac Cardiovasc Surg Pediatr Card Surg Annu. 2004;7:185-91.

6. Jacobs JP, Jacobs ML, Lacour-Gayet FG, Jenkins KJ, Gauvreau K, Bacha E, et al. Stratification of complexity improves the utility and accuracy of outcomes analysis in a multi-institutional congenital heart surgery database: application of the Risk Adjustment in Congenital Heart Surgery (RACHS-1) and Aristotle Systems in the Society of Thoracic Surgeons (STS) Congenital Heart Surgery Database. Pediatr Cardiol. 2009;30:1117-30.

7. Welke KF, O'Brien SM, Peterson ED, Ungerleider RM, Jacobs ML, Jacobs JP. The complex relationship between pediatric cardiac surgical case volumes and mortality rates in a national clinical database. J Thorac Cardiovasc Surg. 2009; $137: 1133-40$

8. Jacobs JP, Quintessenza JA, Burke RP, Bleiweis MS, Byrne BJ, Ceithaml EL, et al. Analysis of regional congenital cardiac surgical outcomes in Florida using the Society of Thoracic Surgeons Congenital Heart Surgery Database. Cardiol Young. 2009; 19:360-9.

9. Jacobs JP, Mavroudis C, Jacobs ML, Maruszewski B, Tchervenkov CI, LacourGayet FG, et al. What is operative mortality? Defining death in a surgical registry database: a report of the STS Congenital Database Taskforce and the Joint EACTS-STS Congenital Database Committee. Ann Thorac Surg. 2006;81: 1937-41.
10. Murakami A, Kitahori K, Takamoto T, Miyata H, Konuma T, Matsumura G, et al. Updated cardiovascular surgery. Progress in JCCVSD (Japan Congenital Cardio-Vascular Surgery Database. Pediatr Cardiol Card Surg. 2010; 26(Suppl):S151.

11. Gaynor JW, Jacobs JP, Jacobs ML, Elliott MJ, Lacour-Gayet F, Tchervenkov CI, et al, International Congenital Heart Surgery Nomenclature and Database Project, Congenital Heart Surgery Committees of the Society of Thoracic Surgeons, European Association for Cardio-Thoracic Surgery. Congenital Heart Surgery Nomenclature and Database Project: update and proposed data harvest. Ann Thorac Surg. 2002;73:1016-8.

12. Sakata R, Fujii Y, Kuwano H. Thoracic and cardiovascular surgery in Japan during 2008: annual report by The Japanese Association for Thoracic Surgery. Gen Thorac Cardiovasc Surg. 2010;58:356-83. Erratum in: Gen Thorac Cardiovasc Surg. 2010;58:493.

13. Hanley JA, McNeil BJ. The meaning and use of the area under a receiver operating characteristic (ROC) curve. Radiology. 1982;143:29-36.

14. Welsby IJ, Bennett-Guerrero E, Atwell D, White WD, Newman MF, Smith PK, et al. The association of complication type with mortality and prolonged stay after cardiac surgery with cardiopulmonary bypass. Anesth Analg. 2002;94:1072-8.

15. Motomura N, Miyata H, Tsukihara H, Okada M, Takamoto S, Japan Cardiovascular Surgery Database Organization. First report on 30-day and operative mortality in risk model of isolated coronary artery bypass grafting in Japan. Ann Thorac Surg. 2008;86:1866-72.

16. Ferraris VA, Ferraris SP, Singh A. Operative outcome and hospital cost. J Thorac Cardiovasc Surg. 1998;115:593-602; discussion 602-3.

17. Clarke DR, Breen LS, Jacobs ML, Franklin RC, Tobota Z, Maruszewski B, et al. Verification of data in congenital cardiac surgery. Cardiol Young. 2008;18(Suppl 2):177-87.

18. Damhuis RA, Wijnhoven BP, Plaisier PW, Kirkels WJ, Kranse R, van Lanschot JJ. Comparison of 30-day, 90-day and in-hospital postoperative mortality for eight different cancer types. Br J Surg. 2012;99:1149-54.

19. Pasquali SK, He X, Jacobs JP, Jacobs ML, O'Brien SM, Gaynor JW. Evaluation of failure to rescue as a quality metric in pediatric heart surgery: an analysis of the STS Congenital Heart Surgery Database. Ann Thorac Surg. 2012;94:573-9; discussion 579-80.

\title{
EDITORIAL COMMENTARY
}

\section{Risk models for pediatric and congenital cardiac surgery}

\author{
Jeffrey P. Jacobs, MD
}

See related article on pages 2201-6.

The Japan Congenital Cardiovascular Surgery Database (JCCVSD) is to be congratulated for their important contribution to congenital and pediatric cardiac care in

From Johns Hopkins All Children's Heart Institute, All Children's Hospital and Florida Hospital for Children, Johns Hopkins University, Saint Petersburg, Fla. Disclosures: Author has nothing to disclose with regard to commercial support. Received for publication Sept 29, 2014; accepted for publication Sept 29, 2014.

Address for reprints: Jeffrey P. Jacobs, MD, Johns Hopkins All Children's Heart Institute, 601 Fifth Street South, Suite 607, Saint Petersburg, FL 33701 (E-mail: jeffjacobs@msn.com).

J Thorac Cardiovasc Surg 2014;148:2206-7

$0022-5223 / \$ 36.00$

Copyright (c) 2014 by The American Association for Thoracic Surgery

http://dx.doi.org/10.1016/j.jtcvs.2014.09.105 the domains of outcomes analysis and quality improvement. ${ }^{1}$ The authors have described the development of sophisticated congenital cardiac surgical risk models for short-term and mid-term outcomes based on integrated data from nationwide hospitals in Japan, using JCCVSD. This contribution is important because it describes the development of congenital cardiac surgical risk models that add to extant risk models by both the incorporation of several patient-specific variables and increased duration of follow-up.

JCCVSD uses the same nomenclature (International Pediatric and Congenital Cardiac Code) and data standards that are used in the Society of Thoracic Surgeons Congenital Heart Surgery Database (STS-CHSD) and the European Association for Cardio-Thoracic Surgery Congenital Heart Surgery Database (EACTS-CHSD). 